\title{
Towards the development of a Charisma Inventory for Teaching Effectiveness (CITE) in the Philippine classroom
}

\author{
Torio, Von Anthony G. $\square$ \\ Philippine Normal University, Manila, Philippines (torio.vag@pnu.edu.ph) \\ De La Salle, Manila, Philippines \\ Torio, Myla Zenaida C. \\ Philippine Normal University, Manila, Philippines (cabrillas.mzc@pnu.edu.ph) \\ University of the Philippines, Diliman, Quezon City, Philippines
}

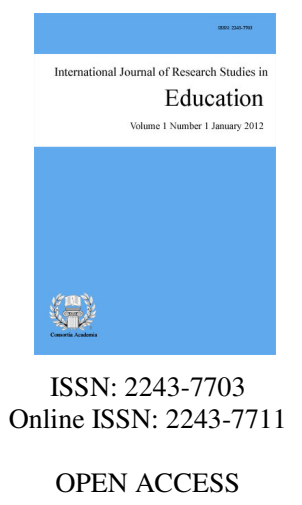

Received: 2 November 2016

Revised: 3 February 2017

Available Online: 3 April 2017 DOI: $10.5861 /$ ijrse.2017.1671

Accepted: 19 February 2017

\begin{abstract}
Teaching effectiveness is essential in bringing about classroom achievement. Charisma is strongly linked with teaching effectiveness. Huang and Lin (2014) named four factors related to charisma which were utilized in this study. The factors include: 1) character traits, 2) knowledge, 3) humor, and 4) teaching techniques. Using these factors, the proponents aimed to develop an instrument to measure charisma called, Charisma Inventory for teaching effectiveness (CITE). The development of the instrument followed the Development research design that involved two phases. The first phase is the development of the instrument and second phase is the tryout of the instrument. Using the four areas of charisma according to Huang and Lin (2014), a new set of 10 items per area were developed giving a total of 40 items in all. The second phase involved the utilization of the instrument where the teaching effectiveness of an identified faculty was determined through student evaluation. The result of the evaluation revealed that all areas of the identified faculty were outstanding with character traits being the strongest area and teaching techniques being the weakest. The results of the evaluation using the instrument provided insights as to improving classroom practices and addressing classroom achievement. Further tests may be done with the instrument in order to determine some other psychometric characteristics of the developed instrument.
\end{abstract}

Keywords: charisma; teaching effectiveness; Philippines; achievement; teaching inventory 


\section{Towards the development of a Charisma Inventory for Teaching Effectiveness (CITE) in the Philippine classroom}

\section{Introduction}

There is a complex interplay of several factors to consider when dealing with learning in school classrooms. A common definition of learning is, "a change in behavior". Several theories and philosophies were exhausted in several references both printed and over the internet. Some of these theories are Neuroscience, Behaviorism, Social Cognitive theory, information processing, and many others (Schunk, 2012; Wilson \& Peterson, 2006). According to Wilson and Peterson, the different theories of learning may be clustered into three: 1) learning as a process of active engagement; 2) learning as individual and social; and 3) learner differences as resources to be used, not obstacles to be confronted.

In majority of the literature about learning and achievement, there is a strong recognition that both should be quantified and measured. Many national and international examinations had been instituted to do the task of measuring achievement. Two international examinations are popular in the field of mathematics and Science: 1) Trends in International Mathematics and Science Study (TIMSS), and the 2) Program for International Student Assessment (PISA). While TIMSS focuses on Math and Science, PISA focuses on Reading, Science and Mathematics.

One of the most important factors affecting students' academic achievement is teacher-related. It is therefore important to establish teaching effectiveness by looking at factors that contributes to student achievement. Several studies had been conducted to establish the link between teacher factors and student achievement (Haider \& Hussain, 2014; Kosgei, Mise, Odera, \& Ayugi, 2013; Kimani, Kara, \& Njagi, 2013). A big factor in the Philippines related to teaching effectiveness is charisma. It is the aim of this study to develop a pilot instrument to measure charisma as related to teaching effectiveness in the classroom.

\subsection{School Achievement}

Learning in classes is closely associated to student achievement. Several factors contribute to the achievement of students in classes. These factors include but is not limited to the following complex variables: 1) Home Context variables, 2) School-level context variables, 3) Classroom input variables, 4) Classroom process variables (W. Huit, M. Huitt, Monettit, \& Hummel, 2009). Three home context variables were identified to be significantly contributing to the school achievement of students, 1) home environment, 2) socioeconomic status (SES), and 3) parental involvement according to Hattie (2009) (as cited in Huit et al., 2009, p. 3). Hattie (2009) also identified twenty-one school-level context variables which were clustered into: 1) school characteristic, 2) school-level processes, and 3) school-wide implementation of the curriculum.

Another cluster of factors is school-level context variables. There were twenty-one school-level context variables identified by Hattie (2009). The cluster includes one factor associated to school characteristic, five related to school-level processes, and fourteen under school-wide implementation of the curriculum. The only factor that falls under school characteristic is class size. This is supported by the study of NCES (2000) in the United States, a substantive correlation was found to exist between class size and academic achievement. The next cluster of variables is classroom input variables. This cluster of variables refers to the characteristics of the teachers and the students prior to entry in the classroom. Another set of three variables had been identified by Hattie (2009) under this cluster: 1) microteaching during pre-service training, 2) professional development of faculty on school achievement, and 3) teacher expectations.

The last cluster of variables that can directly affect student achievement is classroom process variables. 
Towards the development of a Charisma Inventory for Teaching Effectiveness in the Philippine classroom

Under this cluster are three subcategories according to Hattie (2009). These subcategories are: 1) teacher behavior, 2) student behavior, and 3) miscellaneous factors (e.g., classroom climate). Higher student achievement is associated to more efficient practices in school and greater potential on the end of the students to contribute to community development, nation building and international competitiveness.

\subsection{The Philippines and School Achievement}

School achievement is believed to be a big factor towards achievement of national development and international competitiveness. The Philippines recognizes the primordial role of education. The recognition of this role is well articulated in the constitution of the Philippines, "The state shall promote and protect the right of all citizens to quality education at all levels, and shall take appropriate steps to make such education accessible to all" (Phil. Const., Art. XIV, s. 1). Though the Philippine constitution makes recognition of the importance of education, the Philippines is still not spared from issues pertaining to education. The Philippine Educational issues including the role that education takes in national development (Durban, \& Catalan, 2012). Filipinos give a high regard to education and even considers it to be, "a vehicle for social mobility" (Durban, \& Catalan, 2012).

In the Philippines, School Achievement is a significant term observed in the teaching and learning process. Every year, a National Achievement test is conducted to help measure how the students were able to meet the competencies expected from key grade levels. The grade levels who take the achievement test include those in grades 3, 6, 8, and 10 with some variants in previous years. The examination is facilitated by the National Educational Testing and Research Center. Previous measures of achievements in the Philippines include the National Elementary Achievement Test and the National Secondary Achievement Test for elementary and secondary level students respectively.

We have a similar fate in the international arena in terms of performance in standardized examinations. In the report of the National Center for Education Statistics of the United States (2004), we have consistently ranked either third or fourth from the last. In the most recent TIMSS that we have participated, only 10 countries participated and the Philippines ranked last. In previous TIMSS, such as the 2003 TIMSS, we have ranked $23^{\text {rd }}$ of the 25 countries both for Science and Math. In 2005, the Philippines ranked $34^{\text {th }}$ of 38 countries in High School Math and $43^{\text {rd }}$ of 46 countries in High School Science. The Philippines did not participate in PISA which is expected to release results by December 2016.

\subsection{Review about Charisma}

Charisma is a term that is not just popular in the Philippines but is also recognized in other countries. It is a term that is considered to be understood in most culture. A term that can easily be used by lay people to refer usually to leaders. Cambridge online dictionary defines this term as a special power that some people have naturally that makes them able to influence other people and attract their attention and admiration. It is common that the term charisma is linked with leadership and other professionals (Walton, 2016; Grabo \& Vugt, 2016). Grabo and Vugt (2016) defined a charismatic leader as one who is able to attract the attention of other group members and serve as a focal point for aligning and synchronizing prosocial orientations in followers, suppressing sensitivity to cooperative risks, and enhancing the salience of perceived cooperative rewards.

In an article by Walton (2016) about the charisma effect, he cited that there are factors that can in some ways affect charisma such as sleep, mystery, height, and mental quickness. A good enough sleep was found to help increase charisma. A bit of mystery can also help improve charisma. Leaders with mental quickness and good height can also help increase charisma. Walton also mentioned that charisma can be taught. He cited the study of Antonakis et al. (2016) about, "Can charisma be taught?" where researchers trained middle managers and MBA students for 30 to 90 hours in 12 "charismatic leadership tactics". These tactics include using metaphors and gestures, and others. Their findings revealed their charisma improved.

Charisma was considered to be a gift that is ill-defined and ill-measured (Antonakis et al., 2016). It is 
considered to be ill-defined since exemplars are used to define it or by the use of its outcomes as described by Antonakis et al. (2011). In addition, Antonakis et al., (2011) also mentioned that the use of typical behavioral questionnaires, might not be capturing the construct appropriately and such measures of charisma might be outcomes of other factors themselves. In earlier versions, charisma is well associated with leadership. A charismatic leader is most of the times associated with a transformational leader (House \& Jacobsen, 1992). House and Jacobsen (1992) detailed that a social situation becomes conducive to a charismatic leader when one of more of the following four conditions is/are applicable: 1) when important moral values are perceived to be involved; 2) when the relationship between performance and goals is unclear and ambiguous; 3) when the situation is unstable; and 4) when it requires exceptional efforts. Shamir, House, and Arthur (1993) used charismatic and transformational as interchangeable terms that may describe leaders. They further cited that such leadership has profound effects on followers. However, they found that with several literatures reviewed, none was able to explain the process by which the effects were achieved (Shamir, House, \& Arthur, 1993)

Charisma is not limited to leaders occupying certain positions. Charisma is also a must for teachers since it is inherent in the task of professional teachers to influence learners to become good students. The idea of charisma is linked with teaching effectiveness. In the study of Huang and Lin (2014), they were able to identify four factors associated to charisma. These factors are: 1) knowledge, 2) character traits, 3) teaching techniques, and 4) humor. They were able to develop an instrument to measure charisma and were able to produce an instrument called: Inventory of Teaching Charisma in College classroom. It is the aim of this study to come up with the same instrument as Huang and Lin (2014) for measuring charisma in teaching. It is one of the goals of the study to make the measure of charisma more relevant to the Philippine setting.

\section{Methods}

\subsection{Research Design}

The researchers used the development research design, specifically type 1 development research design. Seels and Richey (1994) defined development research method as the systematic study if designing, developing and evaluating instructional programs, processes and products that must meet the criteria of internal consistency and effectiveness. According to Richey and Klein (2005), there are two types of development research, referred to as type 1 and type 2. Richey and Klein (2005) further described both types as follows. Type 1 developmental studies focus upon a given instructional product, program, process, or tool. Type 1 also reflects an interest in identifying either general development principles or situation-specific recommendations. Type 1 studies address not only product design and development, but evaluation as well. Type 2 studies, on the other had, focus upon a given design, development, or evaluation model or processes. They may involve constructing and validating unique design models and processes, as well as identifying those conditions that facilitate their successful use.

\subsection{Participants of the Study}

There are two types of participants in the study. The first type includes designers/contributors, validators, and evaluators. The second type is the clients of the study. The first type of participants is the in-service teachers who served three functions: 1) designers/contributors of item statements for the charisma inventory instrument; 2) validators of the item statements developed by contributors; and 3) evaluators of the item-statements. The following table shows the descriptive of the in-service teacher-participants. While, Table 2 shows the second set of participants came from a population of basic education and tertiary level students. The students served as recipients of the developed instrument who utilized it to rate the identified faculty. The following is the pool of participants which served as the population from where a sample of participants was taken using random sampling. 
Towards the development of a Charisma Inventory for Teaching Effectiveness in the Philippine classroom

Table 1

Descriptive of in-service teachers

\begin{tabular}{lcc|lc|lc}
\hline \multicolumn{1}{c}{ Gender } & $n$ & $\%$ & \multicolumn{2}{c|}{ Age } & \multicolumn{2}{c}{ Years in Service } \\
\hline Male & 23 & 29.5 & Highest & 58 & Highest & 33 \\
Female & 53 & 67.9 & Least & 23 & Least & 1 \\
No Response & 2 & 2.6 & No Response & 3 & No Response & 3 \\
$r$ Total & 78 & 100 & Average & 40.37 & Average & 13.06 \\
& & & SD & 9.22 & SD & 9.58 \\
\hline
\end{tabular}

Table 2

Descriptive of the population of students

\begin{tabular}{lcc}
\hline \multicolumn{1}{c}{ Participants } & $n$ & $\%$ \\
\hline Grade 9 & 64 & 32.65 \\
Grade 10 & 67 & 34.18 \\
Tertiary level & 65 & 33.16 \\
$\quad$ Total & 196 & 100 \\
\hline
\end{tabular}

From the pool of 196, a randomly sampled set of students were determined electronically. An electronic survey was generated to get a sample of participants from the population. Social networking was used to get the samples. Only those who responded electronically were allowed to do the evaluation. The following is the descriptive of the participants:

Table 3

Descriptive of the sample of students

\begin{tabular}{lcc}
\hline Participants & $n$ & $\%$ \\
\hline Grade 9 & 14 & 50.00 \\
Grade 10 & 6 & 21.43 \\
Tertiary level & 8 & 28.57 \\
$\quad$ Total & 196 & 100 \\
\hline
\end{tabular}

\subsection{Research Procedures}

There are three phases followed in the development of the instrument. The first phase involved the development, validation and evaluation of item statements within the Philippine context. The second phase is the use of constant comparative method to get the common statements from the participants using the four areas introduced by Huang and Lin (2014). The third and last phase involves the utilization of the instrument in classes.

\section{First Phase: Development of the item-statements}

A national seminar-workshop in research for teachers was organized where teacher-participation was made voluntary. The seminar was endorsed by the Department of Education. A pool of 78 in-service teacher-participants joined the seminar in the development, validation and evaluation of the instrument. The sub-phases of this portion is as follows: 1) Presentation of the benchmark instrument and the benchmark item statements; 2) Writing of item statements through Focus group discussion; 3) critiquing and evaluation of the item statements, 4) Presentation of the item statements in the bigger group.

In the first sub-phase, the original instrument of Huang and Lin (2014) became the primary source of the four areas of charisma: 1) knowledge, 2) character traits, 3) teaching techniques, and 4) humor. This was presented to the teacher-participants. They were also allowed to use the instrument for self-assessment. The 
second sub-phase involved the writing of the different item-statements per area. Each of the participants were requested to write three item statements per area. The next sub-phase is evaluation, validation and critiquing of the item-statements. The teachers were tasked to form small groups of 6 to 8 members, forming a total of 12 groups. Each group was tasked to choose a facilitator. All the groups were tasked to come up with final three item statements per area. The last sub-phase involved the presentation and critiquing of the bigger group of participants. Here, the representatives of the groups presented their item statements. Comments about the item-statements were made for improvement.

\section{Second Phase: Coding of the statements}

The coding of the statements is essential in coming up with the final pool of item statements. The coding scheme follows part of the Constant comparative method as cited in the work of V. Torio and M. Torio (2015). Specifically, part of Strauss and Corbin's (2008) levels of analyses were used: 1) open coding, b) axial coding, and c) selective coding. For the open coding step, the gathered responses of the twelve groups were encoded. Axial coding was then done by putting together data that seem to match and fit. The last step is the selective coding where the final set of item statements was identified.

\section{Third Phase: Utilization of the instrument in classes}

The final instrument called Charisma Inventory for Teaching Effectiveness (CITE) was used in a set of three clusters. One cluster is a group of grade 9 students, another is a group of grade 10 students and the last is the group of tertiary level students. The groups of students were handled by the identified faculty for at least three quarters of around 6 months prior to the utilization of the instrument. An electronic version of the instrument was made. An announcement for evaluation was made through a social networking site and a limited time was given to determine the sample of participants. Only those who responded to the electronic sample was used as a means to limit the data that will be analyzed for the purpose of the study.

\section{Results and Discussion}

\subsection{Results of First Phase: Development of Item Statements}

The original instrument of Huang and Lin (2014) called Inventory of Teaching Charisma in the College Classroom (ITCCC) consists of 32 items and is intended to measure the students' perceptive degree of the teaching charisma of their teachers. The students are tasked to respond to a 5-point Likert-type scale from 1 (never true) to 5 (always true). The instrument has minimal issues about item homogeneity and distribution. The breakdown of the items for the four areas is as follows:

\section{Table 4}

Descriptive of the sample of students

\begin{tabular}{lc}
\hline \multicolumn{1}{c}{ Teaching Charisma Area } & Number of items \\
\hline Character traits & 6 \\
Knowledge & 7 \\
Humor & 6 \\
Teaching Techniques & 4 \\
\hline
\end{tabular}

Majority of the statements are also framed as in the form, "My teacher ..." with an exemption of one item which falls under Area 2: Knowledge which is expressed as, "I admire ...". In order to address concerns about equal distribution of items, the constant comparative method target is to come up with equal number of item statements for the different areas and consistent framing of the item-statements. The following table shows the results of the constant comparative coding method with three sample statements per area: 
Table 5

Results of the Constant Comparative Method

\begin{tabular}{ll}
\hline Area 1. Character Traits & $\begin{array}{l}\text { Prepares his/her task/lesson before coming to class. } \\
\text { Maximizes the allotted time and provides maximum learning } \\
\end{array}$ \\
\hline Exercises proper decorum, and sets a good example for his learners \\
\hline Krea 2. Knowledge & Haws and uses several materials necessary for effective instruction \\
& Responds to a variety of students' classroom needs \\
\hline Area 3. Humor & Adopts trending educational expressions that enhances communication skills \\
& Facilitates fun, relax and exciting teaching or learning \\
& Maintains a pleasant personality at all times. \\
\hline Area 4. Teaching & Adopts learner-centered strategies such as inquiry-based and collaboration \\
Techniques & approaches \\
& Uses brain motivation techniques to leash out the interest of students \\
& Engages the students in real life situations \\
\hline
\end{tabular}

A total of ten item statements were taken from the responses of the 12 groups. The table shows three samples per area. The result of the constant comparative method does not anymore include pronouns to eliminate issues of homogeneity. Instead, present tense of the verb was used for each of the item statements.

\subsection{Results of Second Phase: Evaluation of the Students}

In evaluating the identified faculty, the 5 point Likert-type was utilized similar to that of the ITCCC instrument of Huang and Lin (2014). The 28 representative respondents rated the faculty on the subject handled by the faculty member in their respective levels. The results of the evaluation of the students were compared to the following qualitative descriptions:

Table 6

Qualitative Description and Interpretation of Charisma Scores

\begin{tabular}{cll}
\hline Range of Scores & \multicolumn{1}{c}{ Interpretation } & \multicolumn{1}{c}{ Qualitative Description } \\
\hline $4.50-5.00$ & Always True & Outstanding \\
$3.50-4.49$ & Most of the time True & Excellent \\
$2.50-3.49$ & Seldom True & Very Satisfactory \\
$1.50-2.49$ & Rarely True & Satisfactory \\
$1-1.49$ & Never True & Needs Improvement \\
\hline
\end{tabular}

Table 7

Summary of the Results of the Evaluation of the Students

\begin{tabular}{lccc}
\hline \multicolumn{1}{c}{ Areas of Charisma } & Mean & SD & Interpretation \\
\hline I. Character Traits & 4.70 & 0.502 & Outstanding \\
II. Humor & 4.66 & 0.533 & Outstanding \\
III. Knowledge & 4.61 & 0.613 & Outstanding \\
IV. Teaching Techniques & 4.51 & 0.688 & Outstanding \\
\hline
\end{tabular}

The results of the evaluation revealed that the chosen faculty member did outstanding performance in all areas of charisma as evaluated by samples from both tertiary and basic education students. It further revealed the strongest area of the teacher which is character traits and his weakest being teaching techniques. The consistency of the instrument was also determined using SPSS. The alpha coefficient was calculated which gave a Cronbach alpha value of 0.913 (items $=40$ ). This showed that the instrument has high reliability.

\section{Discussion}

Teachers are considered to be experts in the field, especially when they have already taught for decades inside the classroom. Inherent in teachers is their ability to influence others, vis-à-vis, and their students. Their 
ability to influence others may be an indication of their charisma in teaching. Charisma in teaching can be measured using an instrument with identified areas. The study of Huang and Lin (2014) in Taiwan was able to show how charisma may be quantified using an instrument that they have developed. A firm frame was already laid by them in the area of charisma and is worth emulating. However, there are some concerns as to the use of the original instrument of Huang and Lin (2014).

The applicability of any instrument in the Philippines becomes in question since some cultural considerations or constraints may limit the generalizability of the results. Thus, one of the main aims of the study is to make the item-statements contextualized in the Philippine setting. To ensure contextualization, the item statements were taken from in-service teachers. In the development of the item statements through constant comparative, some statements become chunked with descriptions which may have both pros and cons. One of the major advantages is that it will be able to comprehensively address the concept of charisma. A major disadvantage is the genuine clustering of the characteristics. Some concerns with the original instrument were also addressed. These concerns are the homogeneity of the items and the equality in terms of item-distribution of the areas. The developed item-statements do not anymore reflect pronouns. In addition, an equal number of item-statements are now considered per area.

\section{Conclusion}

The main aim of this study is to come up with an instrument to measure charisma in teaching. Charisma is believed to be an influential factor in effective teaching. The original instrument of Huang and Lin (2014) poses cultural concerns and is thus limiting in generalizability when used in the Philippine context. The developed instrument is a potential alternative to measure teaching charisma which is equated to teaching effectiveness. This new instrument addresses contextualization constraints through item development by practitioners in the field. Though the results of the evaluation of the chosen faculty will not be an exact measure of teaching effectiveness, it gives an idea about the areas of strengths and weaknesses that teachers can improve on. If teachers are given an idea as regards strengths and weaknesses, they will gain insights on improving their craft and becoming better in their field. Students will also feel valued since they know that they take part in the way that they learn. Their inputs to help better practices in the classroom through evaluating their teachers will hopefully improve classroom practices in the long run. Further tests can still be done with the developed instrument to limit the item statements to those that really matters and to determine some other psychometric characteristics of the test. Improvements on the instrument will further give insights as to which really matters in Philippine classes.

\section{References}

Antonakis, J., Bastardoz, N., Jacquart, P., \& Boas, S. (2016). Charisma: An ill-defined and ill-measured gift. Annual Review of Organizational Psychology and Organizational Behavior, 3, 293-319. https://doi.org/10.1146/annurev-orgpsych-041015-062305

Antonakis, J., Fenley, M., \& Liechti, S. (2011). Can charisma be taught? Tests of two interventions. Academy of Management Learning \& Education, 10(3), 374-396. https://doi.org/10.5465/amle.2010.0012

Charisma. (n.d.). In Cambridge Dictionary online. Retrieved from http://dictionary.cambridge.org/dictionary/english/charisma

Durban, J. M., \& Catalan, R. D. (2012). Issues and concerns of Philippine education through the years. Asian Journal of Social Sciences \& Humanities, 1(2), 61-69.

Grabo, A., \& Vugt, M. V. (2016). Charismatic leadership and the evolution of cooperation. Evolution \& Human Behavior: Official Journal of the Human Behavior and Evolution Society, 37(5), 399-406. https://doi.org/10.1016/j.evolhumbehav.2016.03.005

Haider, S. Z., \& Hussain, A. (2014). Relationship between teacher factors and student achievement: A correlational study of secondary schools. US-China Education Review A, 4(7), 465-480.

Hattie, J. (2009). Visible learning: A synthesis of over 800 meta-analyses relating to achievement. London \& New York: Routledge. 
Towards the development of a Charisma Inventory for Teaching Effectiveness in the Philippine classroom

House, R. J., \& Jacobsen, C. (1992). The dynamics of charismatic leadership in organizations. Retrieved from http://www.systemdynamics.org/conferences/1992/proceed/pdfs/jacob267.pdf

Huang, Y. C., \& Lin, S. H. (2014). Assessment of charisma as a factor in effective teaching. Educational Technology \& Society, 17(2), 284-295.

Huit, W., Huitt, M., Monetti, D., \& Hummel, J. (2009). A systems-based synthesis of research related to improving students' academic performance. Paper presented at the $3^{\text {rd }}$ International City Break Conference sponsored by Athens Institute for Education and Research (ATINER), Athens, Greece. Retrieved from http://www.edpsychcineractive.org/papers/improving-school-achievement.pdf

Kimani, G. N., Kara, A. M., \& Njagi, L. W. (2013). Teacher factors influencing students' academic achievement in secondary schools in Nyandarua County, Kenya. International Journal of Education and Research, 1(3), 1-14.

Kosgei, A., Mise, J. K., Odera, O., \& Ayugi, M. E. (2013). Influence of teacher characteristics on students' academic achievement among secondary schools. Journal of Education and Practice, 4(3), 76-82.

Philippine Constitution. (1987). Phil. Const. Art. XIV, s. 1.

Richey, R. C., \& Klein, J. D. (2005). Developmental research methods: Creating knowledge from instructional design and development practice. Journal of Computing in Higher Education, 16(2), 23-38. https://doi.org/10.1007/BF02961473

Schunk, D. H. (2012). Learning theories: An educational perspective (6th ed.). Boston, MA: Allyn \& Bacon.

Seels, B. B., \& Richey, R. C. (1994). Instructional technology: The definition and domains of the field. Washington, DC: Association for Educational Communications and Technology.

Shamir, B., House, R., \& Arthur, M. (1993). The motivational effects of charismatic leadership: A self-concept based theory. Organization Science, 4, 577-594. https://doi.org/10.1287/orsc.4.4.577

Strauss, A., \& Corbin, J. (2008). Basics of qualitative research: Grounded theory procedures and techniques (3rd ed.). Newbury Park. CA: Sage.

Torio, V A. G., \& Torio, M. Z. C. (2016). The dilemma of giving mathematics homework from the perspective of pre-service elementary teachers. International Journal of Research Studies in Education, 5(1), 19-29. https://doi.org/10.5861/ijrse.2015.1175

United States Department of Education, Institute of Education Sciences, National Center for Education Statistics. (2000). School-level correlates of academic achievement: Student assessment scores in SASS public schools. Author.

United States Department of Education, Institute of Education Sciences, National Center for Education Statistics. (2004). Highlights from the trends in international mathematics and science study. Author.

Walton, J. (2016). The charisma effect: How to bend people to your will. The Atlantic: Online. Retrieved from http://www.theatlantic.com/magazine/archive/2016/09/the-charisma-effect/492740/

Wilson, S. M., \& Peterson, P. L. (2006). Theories of learning and teaching: What do they mean for educators? (Working paper) National Education Association. 
Torio, V. A. G., \& Torio, M. Z. C. 